\title{
Caracterización Ecológica De Bofedales, Hábitat De Vicuñas Aplicando Metodologías De Teledeteccion Y Sig Estudio De Caso: Reserva De Producción De Fauna Chimborazo
}

\author{
Paulina Beatriz Díaz Moyota \\ Catalina Margarita Verdugo Bernal \\ Carla Sofía Arguello Guadalupe \\ Carlos Arturo Jara Santillán
}

Docente - Investigador de la Facultad de Recursos Naturales ESCUELA SUPERIOR POLITÉCNICA DE CHIMBORAZO - ECUADOR Byron Ernesto Vaca Barahona

Docente - Investigador de la Facultad de Informática y Electrónica ESCUELA SUPERIOR POLITÉCNICA DE CHIMBORAZO - ECUADOR Andrés Alejandro Yépez Villavicencio

Jefe de Informática SIG Y Catastros

EP-EMAPAR - ECUADOR

Brian E. McLaren

Associate Professor - Faculty of Natural Resources Management LAKEHEAD UNIVERSITY - CANADÁ

doi: 10.19044/esj.2016.v12n35p105 URL:http://dx.doi.org/10.19044/esj.2016.v12n35p105

Abstract

This article presents a methodology based on classification of images from Landsat 7 ETM + to classify Andean wetlands known as "Bofedal" (wetland) located in the Fauna Production Reserve Chimborazo. Five of the seven in-situ geo-referenced bofedales belong to this category and two belong to the altiplano.

These georeferenced reservoirs are the principal habitat of the vicuñas that are located within the RPFCH in the jurisdictions of the province of Tungurahua: Río Blanco, "Mocha" Valley area, 472.26 ha, 4400 m.; Chimborazo Province: Bofedal Quebrada Toni, Urbina area, 16.74 ha, 4301 $\mathrm{m}$, bofedal El Refugio (Hermanos Carrel) at the Nevado Chimborazo, 1.44 ha, 4800msnm, and Curi bofedal Pogyo, Chorrera Mirador, 0.34 ha., $4523 \mathrm{~m}$. and in the Bolivar Province: the wetlands Chag Pogyo, Pulinguí San Pablo, 19.36 ha, 4064 meters above sea level. Bofedal Sinche1, the sector "antennas", 8.53 ha. 4167 m., And Sinche2, "Puente Ayora" area, 9.39 ha., 
3981 meters, the latter being Chag Pogyo highland bofedales. The seven bofedales represent $0.93 \%$ (527.87 ha) of the total area of the RPFCH (56653, 27 ha.).

Two images of the satellite Landsat 7 ETM +, from the years 2001 EarthSat, 2004 - USGS and an orthophoto 2013-2014 - GIS land were used. Georeferenced and rectified to capture the spatial and temporal variability of these ecosystems and define the characterization of bofedales in the reserve. For each image two classification methods were used, the supervised classification being the most efficient when representing the four representative classes in the RPFCH: snow, rock, pajonal and bofedal. Since this classification is oriented to objects that takes into account aspects such as shape and texture and not just the spectral information of each pixel. Allowing to obtain information on the characteristics and spatial distribution of the bofedales which was verified and validated later in the field. This process allows the generation of digital cartography with the identification, delimited and distributed bofedales along the RPFCH, representing a total of approximately 1483.94 ha in the RPFCH.

In addition, the Normalized Difference Vegetation Index (NDVI) was applied, which made it possible to differentiate water bodies from other coverages, as well as specifically to know the extent of the reservoirs present in the Reserve, in order to better infer Distribution of vicuñas.

Keywords: Overlapping, Wetlands- Bofedales, RPFCH, Landsat

\section{Resumen}

El presente artículo describe la metodología basada en la clasificación de imágenes de satélite Landsat 7 ETM+ para clasificar humedales alto andinos conocidos como bofedales en la Reserva de Producción de Fauna Chimborazo. Cinco de los siete bofedales georreferenciados in-situ pertenecen a esta categoría y dos pertenecen al altiplano.

Estos bofedales altoandinos georreferenciados son habitat principal de las vicuñas que se ubican dentro de la RPFCH, en las jurisdicciones de la Provincia de Tungurahua: Río Blanco, sector Valle de Mocha, 472,26 ha., 4400 msnm.; Provincia de Chimborazo: Bofedal Quebrada Toni, sector Urbina, 16,74 ha, 4301 msnm, bofedal El Refugio (Hermanos Carrel), en el Nevado Chimborazo, 1,44 ha., 4800msnm, y el bofedal Curi Pogyo, Chorrera Mirador, 0,34 ha., 4523 msnm. Y en la Provincia de Bolívar: el bofedal Chag Pogyo, Pulinguí San Pablo, 19,36 ha., 4064 msnm; Bofedal Sinche1, sector las antenas, 8,53 ha., 4167 msnm., y Sinche2, sector Puente Ayora, 9,39 ha., 3981 msnm, siendo este último y Chag Pogyo bofedales de 
altiplano. Los siete bofedales representan $0.93 \% \quad \mathbf{( 5 2 7 . 8 7}$ ha aproximadamente) del área total de la RPFCH (56653, 27 ha.).

Se utilizaron dos imágenes del satélite Landsat 7 ETM+, de los años 2001 (EarthSat) y 2004 (USGS), además una ortofoto 2013-2014 (SIG tierras). Georreferenciadas y rectificadas para captar la variabilidad espacial y temporal de estos ecosistemas y definir la caracterización de bofedales en la reserva. Para cada imagen se usó dos métodos de clasificación, siendo la clasificación supervisada la más eficiente al representar las cuatro clases representativas en la RPFCH: nieve, roca, pajonal y bofedal. Ya que ésta clasificación se orienta a objetos que tiene en cuenta aspectos como la forma y la textura y no sólo la información espectral de cada píxel. Permitiendo obtener información sobre las características y distribución espacial de los bofedales la cual fue verificada y validada posteriormente en campo. Este proceso permitió generar cartografía digital con los bofedales identificados, delimitados y distribuidos a lo largo de la RPFCH, representando un total 1483.94 ha aproximadamente en la RPFCH a año 2004.

Además, se aplicó el Índice de Vegetación de Diferencia Normalizado (NDVI), el cual permitió diferenciar los cuerpos de agua de otras coberturas, así como también específicamente conocer la extensión de los bofedales presentes en la reserva, con el fin de inferir mejor en la distribución de vicuñas.

Palabras claves: Teledetección, bofedal, RPFCH, Landsat

\section{Introducción}

En el Ecuador, la gestión de los humedales inicia en el año 1990, sin embargo, para esa fecha, la importancia de los humedales aún no era reconocida en el país. Flachier et al. (2009:2). Los humedales cobran importancia desde el año 1997, cuando EcoCiencia junto al ex INEFAN inician el Inventario de los Humedales básicamente en la región costa, extendiéndose luego a todo el país con el proyecto Acciones Prioritarias de Conservación de los humedales ecuatorianos (Briones et al. 2001:11). Sin embargo, la mayoría de estos son costeros o de tierras bajas, por lo que la representatividad de "humedales altoandinos" o "turberas" era nula. Flachier et al. (2009:2).

En el caso de los humedales altoandinos, su gestión se enmarca en la Estrategia Regional de Conservación y Uso Sostenible de los Humedales Altoandinos (2005-2015), que fue aceptada por la Convención de RAMSAR (2008:9), el cual es el único convenio mundial dedicado a impulsar la conservación de estos ecosistemas. Pero muchos de estos colapsan o se degradan como resultado de la deforestación, erosión o pérdida de suelos. MAE. (2006). El Ecuador empezó a trabajar con la Convención RAMSAR 
desde 1991 con el objetivo de realizar esfuerzos de conservación y manejo de los humedales (Echeverría, 2008).

Las turberas son humedales de altura que, debido a las características del suelo del páramo (baja temperatura, alta acidez, escaso oxígeno y bajo contenido de nutrientes) y, obviamente, a la presencia de agua, la materia orgánica se descompone muy lentamente, formándose una acumulación comúnmente conocida como turba (Murillo y Jufosky 2001). Un tipo particular de éstas, son los “bofedales”, conocidos también como oconales, turberas, entre otros; que se ubican en las zonas altoandinas y altiplánicas del país. Los bofedales son hábitats naturales húmedos, con agua permanente, alimentados de diferentes fuentes como manantiales, agua de deshielo, ríos y lluvia. (Alzérreca, et al., 2001:140). En el Ecuador los bofedales también son conocidos como almohadillales (Izurieta 2004). Cárdenas \& Encina, (2008:5). Pero las condiciones ambientales en los bofedales y otros pastizales hacen que estos ecosistemas sean clasificados como frágiles. Izurieta (2005:2). Los bofedales al ser un humedal de altura, poseen una alta productividad para las “vicuñas”, por lo tanto, son de alto interés económico en la región, valor ecológico por su alta biodiversidad en fauna y flora siendo un componente fundamental en el ciclo del agua en la región. Slater A. (2007:34).

La Reserva de Producción de Fauna de Chimborazo, fue establecida como tal dentro del marco de la Estrategia Preliminar para la Conservación de Áreas Silvestres Sobresalientes del Ecuador. ECOLAP y MAE. (2007). El Ecuador en 1976, se adhiere al Convenio para la Conservación de la Vicuña, en 1982 el país ratifica el Convenio sobre Conservación y manejo de la Vicuña en el 1979. Slater A. (2007) En el Ecuador la vicuña se extinguió por diferentes razones, por lo cual los países miembros del Convenio: Chile, Perú y Bolivia deciden apoyar al País con la donación de 100 vicuñas cada uno. MAE. (2011:12). En diciembre de 1993 Bolivia entrega 77 vicuñas que se las ubica en los páramos de la RPFCH, dando de esta manera cumplimiento a uno de los objetivos de la creación de la Reserva y en la actualidad se tiene una población de más de 3000 camélidos aproximadamente de dicha especie. Sí, actualmente las vicuñas sólo ocuparan el ecosistema de vegetación geliturbada y edafoxerófila sub nival paramuna, esta zona estaría al borde de la sobre población, pero los grupos están dispersos en otras zonas de la RPFCH. MAE. (2011:7)

Por otra parte, el Convenio de Ramsar da prioridad a la cartografía de zonas húmedas y recomienda el uso de la Teledetección y los Sistemas de Información Geográfica para la elaboración de inventarios de humedales. El uso de esta técnica permite la identificación y caracterización de estos ecosistemas, en ellos se distinguen clases de bofedales en base a su respuesta espectral. (Vega, 2006). 
En este sentido se propone una metodología aplicando la teledetección y SIG con la finalidad de proveer información relevante para el manejo y conservación de los bofedales cuyo ecosistema es vital para la alimentación de las vicuñas, así como para la actualización del plan de manejo de la misma, considerando que la vicuña en el Ecuador es una especie emblemática y de beneficio social para las comunidades que se encuentran dentro y fuera de la reserva Chimborazo. Flachier et al. (2009:20)

\section{Metodología}

Identificar, visitar, describir y georreferenciar in-situ los bofedales de estudio en diversas zonas de la Reserva.

El presente estudio se realizó en la Reserva de Producción de Fauna de Chimborazo, que se encuentra en la Cordillera Central de la Región Interandina, cuya extensión cubre un área de 58.560 hectáreas en los páramos circundantes a los volcanes Chimborazo (6.310 m.s.n.m.) y Carihuairazo (5.020 m.s.n.m.), bajo jurisdicción de las provincias de Chimborazo (Cantones: Riobamba y Guano), Bolívar (Cantón Guaranda) y Tungurahua (Cantones: Ambato, Tisaleo y Mocha). ECOLAP y MAE. (2007)

\section{Contacto con líderes comunitarios}

Para los diversos recorridos de campo, fue necesaria la presencia de cinco guías conocedores de la zona, mismos que con el acompañamiento y apoyo del Dr. Brian McLaren, de la Lakehead University (Canadá) aportaron y compartieron su conocimiento y fuentes de información pertinentes al ser habitantes cercanos a la Reserva Chimborazo". McLaren, (2011)

- Realización de itinerario y visitas de campo.

Previa realización del trabajo de campo, se crearon itinerarios para visitar los bofedales identificados con anterioridad en un estudio paralelo por el Dr. Brian McLaren, para su georreferenciación y procesamiento de coordenadas obtenidas con tres equipos GPS Garmin csx map60. Se planificó cinco salidas de campo donde se tomaron fotografías de cada bofedal, llenando de las fichas individuales, recolectando muestras de suelo, agua y vegetación y delimitando el perímetro de los bofedales con GPS. Pérez M. (2011:24)

\section{Recopilación de la información primaria \\ - Información ambiental}

Información levantada in-situ, en base a parámetros establecidos para el estudio. Previo a las salidas, se diseñó un modelo general de ficha de campo Se elaboraron matrices para recoger la información más relevante de cada bofedal y su entorno 
- Información cartográfica

Se valoró los trabajos cartográficos elaborados en el Plan de Acción Nacional para el manejo y conservación de la Vicuña, del MAE, 2011. Mapas a una escala 1:135.000 y el Visor del Sistema de Información Geográfica como complemento en dicha revisión, fueron base para el proceso de mapas digitales de los bofedales.

\section{- Georreferenciación de los bofedales}

Una vez identificadas las zonas de estudio se georreferenció siete bofedales, los más representativos y de mayor extensión ubicados a lo largo de la reserva para identificar y caracterizarlas. Se procedió a delimitar y recorrer el perímetro de cada bofedal in-situ, para tomar coordenadas mediante el uso del GPS Garmin map 60 csx. (Datum WGS84, zona 17 S), para su posterior procesamiento digital.

\section{- Procesamiento y Análisis de la información}

La información obtenida se sometió a un proceso de revisión, complementación y estructuración con base en las diferentes fuentes referidas. Los datos georreferenciados de cada bofedal se procesaron mediante el paquete ArcGIS 10.1, obteniendo un nuevo Sistema de información geográfico de los bofedales presentes en la reserva para procesar los mapas requeridos en este estudio.

\section{- Análisis físico químico de agua y suelo}

Con el fin de analizar la contaminación hídrica y parámetros físicos y químicos de cada uno de los bofedales de estudio seleccionados, se tomaron muestras de agua y suelo in situ, para estudiar los siguientes parámetros físico-químicos: Nutrientes, temperatura, $\mathrm{pH}$, oxígeno disuelto, salinidad, conductividad eléctrica y cantidad total de sólidos disueltos. Las muestras fueron analizadas en el laboratorio de Suelos de la Facultad de Recursos Naturales de la Escuela Superior Politécnica de Chimborazo (ESPOCH).

Delimitar y subdividir las principales zonas de distribución de bofedales en la reserva utilizando imágenes de satelitales y el análisis de una respuesta espectral de vegetación.

\section{Recopilación de la información digital \\ - Información cartográfica}

La cartográfica base digitalizada que se manejó para el proceso de geo información de la Reserva obtenida del MAE, misma que fue proporcionada por el SIG Tierras (2014), (SIG de la Reserva Chimborazo, proyección UTM, Datum WGS84 zona 17 Sur), la cual se validó y verificó para su procesamiento final. 


\section{- Información Satelital}

Se tuvo acceso a una ortofoto escala 1:5000 generada a partir de la toma de fotografía aérea 1:20000 con un GSD (Ground Sample Distance) de 30 cm para la sierra, del año 2014, obtenidas del Programa Sistema Nacional de Información y Gestión de Tierras Rurales e Infraestructura Tecnológica. (SIG-Tierras,2014).

Esta ortofoto presenta tres secciones obtenidas en tres fechas distintas la primera entregada el 12/2013 de la zona noreste de la reserva en su mayor parte la Provincia de Tungurahua y parte de Chimborazo, la segunda zona de la provincia de Guaranda 08/2014 y la tercera la de la parte norte de la provincia de Chimborazo sector San Juan. Mismas que tuvieron que ser procesadas para homogenizar color y poder hacer un sólo raster de las 214 cartas que presenta la Reserva. Para poderla procesar. Cabe indicar que las cartas ya estaban orto rectificadas.

Se trabajó con imágenes del satélite Landsat 7 de los sensores ETM+, obtenidas de la aplicación Earth Science Data Interface (ESDI) de la Web Global Land Cover Facility. Se han seleccionado ocho sets de imágenes de satélite multiespectral (7 bandas) que abarcan tres décadas disponibles en formato GEOTIFF rectificadas en el sistema de proyección UTM (Universal Transversa Mercator), WGS84 Zona 17s. Así como el archivo de metadatos de Landsat que abarcan y corresponden a distintas épocas y años, con el fin de recoger la mayor variabilidad de los bofedales, en cuanto al contenido en agua y concentración de solutos y de los cultivos del entorno. Además, se procesó una imagen MDT y se empleó como apoyo a las imágenes de satélite.

Se procesó imágenes de Google Earth, como complemento al estudio, imagen que se georreferenció para la zona de estudio con el Programa ArcGIS 10.1, en el Sistema Geodésico Mundial 1984, proyección UTM, huso $17 \mathrm{~S}$, debido a que todas las imágenes presentaban dicha proyección. Se utilizaron los siete puntos de control de cada bofedal, aceptando un error medio de 0,12 esta imagen servirá principalmente para rellenar espacios que la ortofoto entregada por el SIG Tierras no proporciona pues aún no está disponible la zona de la Provincia de Bolívar principalmente. Todas las escenas se recortaron ajustándolas al área de estudio, zona norte de la RPFCH, con una extensión aproximada de 52683 ha.

\section{Procesamiento y Análisis de la información}

\section{- Componer una imagen satelital de una imagen multiespectral}

Fue necesario unificar todas las bandas de cada set de imágenes Landsat 7 ETM+ en un sólo archivo único, para realizar la clasificación temática, se seleccionaron las bandas 1-7 con excepción de la seis ya que es una banda termal con diferente resolución que generalmente no se usa en 
clasificaciones para uso y cobertura del suelo. García, M.P. \& Pérez, M.E. (1999: 16). Este proceso se realizó con el Software Multispect el cual que nos permite mayor versatilidad al combinar imágenes, permite el traspaso, transformación y análisis de información. Con este programa se generó imágenes (.img). La obtención de los mismos fue en combinación 4-3-2 que por default enlaza las capas.

\section{- Corrección radiométrica}

Paso necesario principalmente en aquellas imágenes de los años 2004, ya que el satélite Landsat 7 ETM+ que ha provisto de información casi ininterrumpida desde su lanzamiento en Julio de 1999, en la actualidad presenta un problema a causa de una falla en el instrumento que corrige las líneas escaneadas, dando como resultado que todas las escenas adquiridas desde el 14 de Julio de 2003 hayan sido colectadas conteniendo franjas inclinadas hacia la izquierda que provocan aproximadamente, la pérdida de un 22\% de la información de cada imagen dando datos inválidos llamados gaps. De todas maneras, se hizo una corrección para todas las imágenes para una mejor calidad espectral y tener uniformidad al procesar las imágenes. El proceso se realizó con la herramienta Layer Stack del programa Erdas 2013, mismo que compila primero las bandas para posteriormente usar focal Analysis el cual corrige al mismo tiempo todas las seis bandas compiladas, el proceso se debe repetir las veces que sea necesario hasta que el bandeado haya retrocedido lo suficiente o casi en su totalidad para poder trabajar en las zonas de estudio.

\section{- Comparación temporal de bofedales}

Se consideró la variación en rasgos de tiempo dentro de la misma superficie del área de estudio. A través de las imágenes clasificadas se puede observar el cambio de la superficie de la vegetación característica de bofedal en diferentes años. La vegetación considerada para clasificar bofedales en imágenes supervisadas tomando como puntos de referencia las coordenadas de cada bofedal donde se presentan especies comunes y dominantes del bofedal. Este proceso se realiza con el Software ERDAS v13

\section{- Composición de bandas}

Para el proceso de combinación de bandas se usó el Software ERDAS v13, el cual generó imágenes (.img), y se realizó mediante la combinación de bandas de las imágenes Landsat 7 ETM+, con el fin de interpretar la respuesta de la actividad clorofílica y presencia de agua. Pérez M. (2011:24). Se escogió la imagen en falso color 4-3-2 que destacan las superficies acuáticas con altas densidades de vegetación, materiales en suspensión. Esto se realizó previo a la combinación de bandas 3-2-1, la cual consigue imágenes en color verdadero. Para identificar cuerpos de agua se realiza otro procedimiento sobre las bandas 4 y 5, donde la combinación de bandas arroja una buena reflectancia representando la diferencia entre 
humedales y tierra, los colores verdes, naranja y marrón representa a la vegetación. Y los colores más obscuros a los humedales. Usando para el estudio la combinación 4-5-3.

- Índice de vegetación NDVI

Para este estudio se empleó el NDVI (Índice de Vegetación de Diferencia Normalizada), de las imágenes unificadas, corregida, multiespectrales, comparación temporal, y composición de bandas. Perry, C., Lautenschlager, L. (1984:13). Que se define como:

\begin{tabular}{|c|c|c|}
\hline \multirow{2}{*}{ NDVI = } & NIR - R & $\begin{array}{l}\text { Siendo: (Landsat } 7 \text { ETM+) } \\
\text { NIR: Banda del infrarrojo cercano (b4) }\end{array}$ \\
\hline & $\mathrm{NIR}+\mathrm{R}$ & $\begin{array}{l}\text { Rango de valores del NDVI varía entre }-1 \text { y } \\
1\end{array}$ \\
\hline
\end{tabular}

\section{- Clasificación digital}

Se usó clasificación supervisadas y no supervisadas de imágenes satelitales. Este proceso se realizó con el Software ERDAS v13 para la ortofoto de la RPFCH haremos un balance de las zonas que reflejan su uso al año 2014. Flachier et al. (2009:9).

Figura 1. Procedimiento metodológico aplicando teledetección y SIG

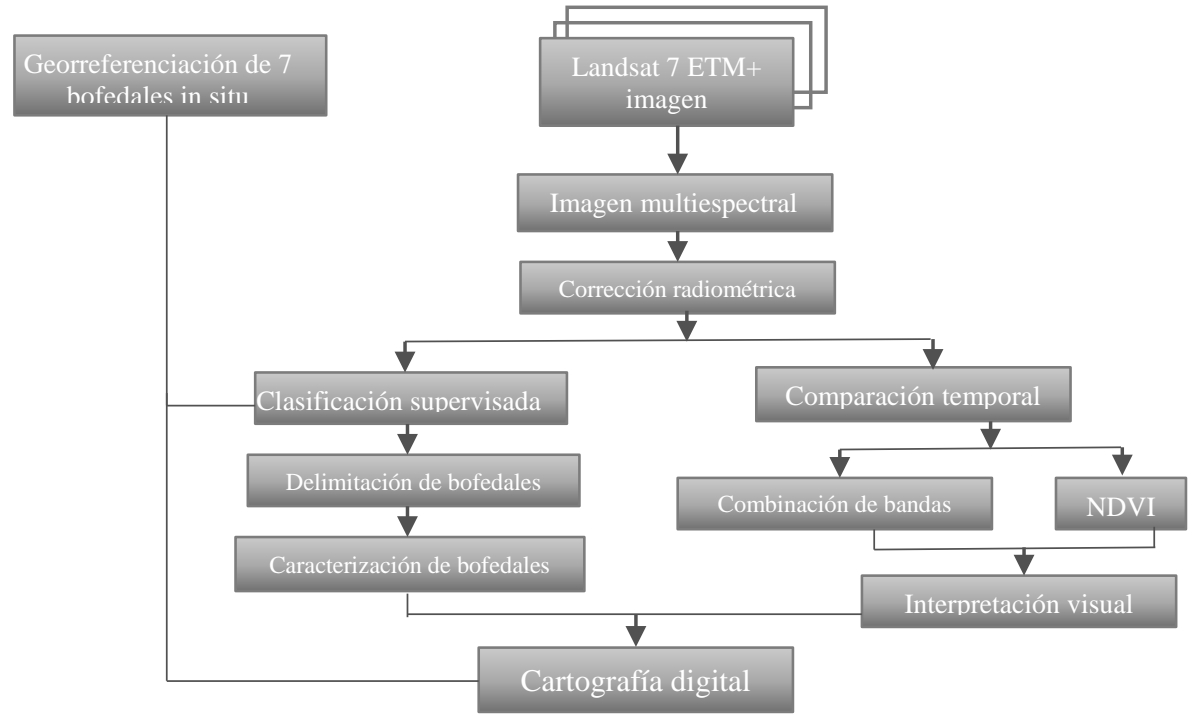

\section{Resultados}

\section{Identificación y descripción de los bofedales}

Se identificaron y georreferenciaron in-situ siete bofedales, dentro de la RPFCH con una proyección UTM, Datum WGS84 y zona 17 Sur y cuyas características más importantes se recogen en la tabla 1. Díaz, P. (2015:32) 
Tabla 1: Bofedales georreferenciados in situ.

\begin{tabular}{|c|c|c|c|c|c|c|c|c|}
\hline N. & $\begin{array}{c}\text { Nombre del } \\
\text { Bofedal }\end{array}$ & Sector & Provincia & $\begin{array}{c}\text { Área } \\
\text { (ha) }\end{array}$ & $\mathrm{x}$ & $\mathrm{y}$ & $\mathrm{z}$ & $\begin{array}{c}\text { Escala } \\
\text { de } \\
\text { mapa }\end{array}$ \\
\hline 1 & Río Blanco & $\begin{array}{c}\text { Valle de } \\
\text { Mocha }\end{array}$ & Tungurahua & $\begin{array}{c}472, \\
26\end{array}$ & 746088 & 9843581 & 4400 & $1: 30000$ \\
\hline 2 & $\begin{array}{c}\text { Quebrada } \\
\text { Toni }\end{array}$ & Urbina & Chimborazo & 16,54 & 748452 & 9837081 & 4301 & $1: 5000$ \\
\hline 3 & $\begin{array}{c}\text { El Refugio } \\
\text { (Hermanos } \\
\text { Carrel) }\end{array}$ & $\begin{array}{c}\text { Nevado } \\
\text { Chimborazo }\end{array}$ & Chimborazo & 1,44 & 739536 & 9836714 & 4800 & $1: 1300$ \\
\hline 4 & $\begin{array}{c}\text { Curi Pogyo } \\
\text { (Chorrera } \\
\text { Mirador) }\end{array}$ & $\begin{array}{c}\text { Nevado } \\
\text { Chimborazo }\end{array}$ & Chimborazo & 0,34 & 741299 & 9834464 & 4523 & $1: 1500$ \\
\hline 5 & $\begin{array}{c}\text { Chag Pogyo } \\
\text { Pulinguí San } \\
\text { Pablo }\end{array}$ & Bolívar & 19,36 & 735460 & 9832179 & 4064 & $1: 10000$ \\
\hline 6 & Sinche1 & $\begin{array}{c}\text { Sinche } \\
\text { (Sector las } \\
\text { antenas) }\end{array}$ & Bolívar & 8,53 & 728712 & 9841002 & 4167 & $1: 5000$ \\
\hline 7 & Sinche2 & $\begin{array}{c}\text { Sinche } \\
\text { (Puente } \\
\text { Ayora) }\end{array}$ & Bolívar & 9,39 & 727816 & 9838200 & 3981 & $1: 5000$ \\
\hline
\end{tabular}

Realizado por: Ing. Paulina B. Díaz M. MSc

\section{Procesamiento y Análisis de la información}

\section{- Interpretación y clasificación de la Cobertura vegetal}

En base al procesamiento de clasificación de cobertura se discriminó cuatro clases para los años 2001 y 2004, Nieve, Roca, Pajonal, Bofedal. Díaz, P. (2015:65)

Tabla 2. Resultados de la clasificación supervisada y no supervisada.

\begin{tabular}{|c|c|c|c|c|c|c|c|c|}
\hline CLASE & \multicolumn{4}{|c|}{ NO SUPERVISADA } & \multicolumn{4}{c|}{ SUPERVISADA } \\
\hline & 2001 & 2004 & diferencia & $\%$ & 2001 & 2004 & diferencia & $\%$ \\
\hline Nieve & 2086,99 & 989,22 & 1097,77 & 52,60 & 2067,39 & 715,17 & 1352,22 & 65,41 \\
\hline Roca & 21356,25 & 15231,48 & 6124,77 & 28,68 & 17563,38 & 16858,62 & 704,76 & 4,01 \\
\hline Pajonal & 12996,74 & 1431,20 & 11565,54 & 88,99 & 30481,91 & 33624,09 & $-3142,18$ & $\begin{array}{c}- \\
10,31\end{array}$ \\
\hline Bofedal & 16234,35 & 27147,51 & $-10913,16$ & $\begin{array}{c}- \\
67,22\end{array}$ & 2566,50 & 1483,94 & 1082,56 & 42,18 \\
\hline
\end{tabular}

Realizado por: Ing. Paulina B. Díaz M

La clasificación no supervisada refleja datos altos de bofedales esto se debe que esta clasificación agrupa la mayoría de unidades vegetales en una misma clase. 


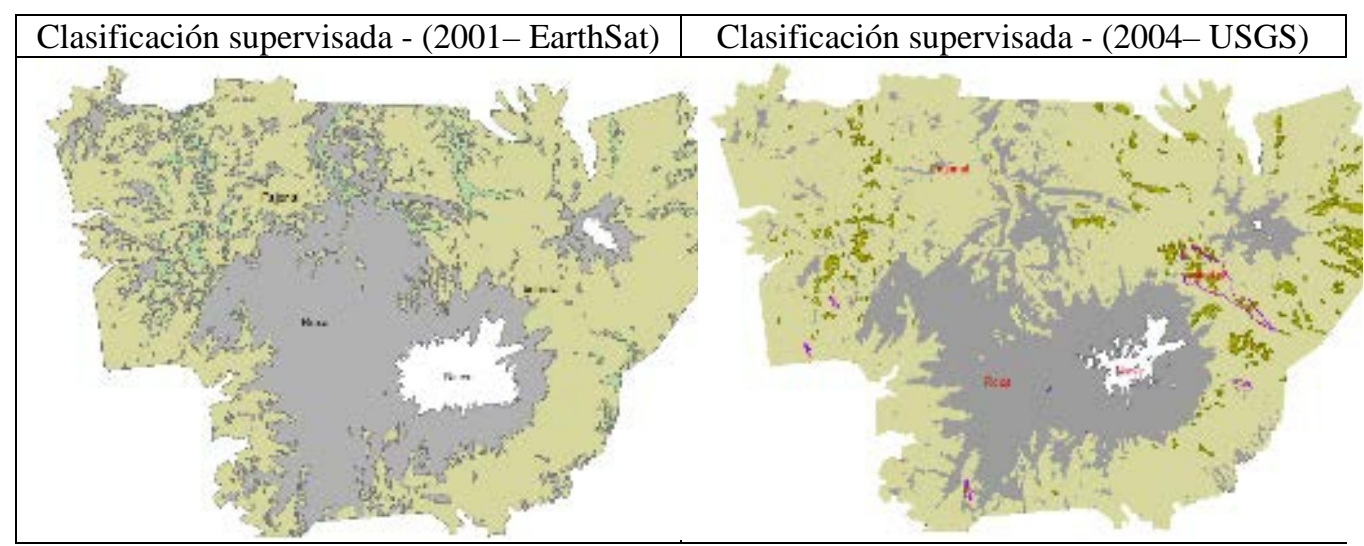

Figura 2. Clasificación Supervisada RPFCH Realizado por: Ing. Paulina B. Díaz M

La clasificación supervisada presenta datos más fiables presente en la reserva y discrimina mejor las unidades estudiadas dando valores para el año 2001: 2566.50 ha y para 2004: 1483.94, presentando una reducción en 4 años de 1082.56 ha., siendo un 42\% aproximadamente de perdida de Bofedales. Los siete bofedales del estudio representan el 35.57\% (527.87 ha) del total Bofedales al 2004 presente en la reserva. Estos resultados se pueden justificar con el aumento de pajonal en la reserva incluso en la zona rocosa se ve un aumento de vegetación en la reserva.

\section{- I Índice de vegetación NDVI}

Esto se valida también con la diferencia de imágenes NDVI donde en el 2004 se refleja un aumento de vegetación ante la reducción de las otras clases. Díaz, P. (2015:66)

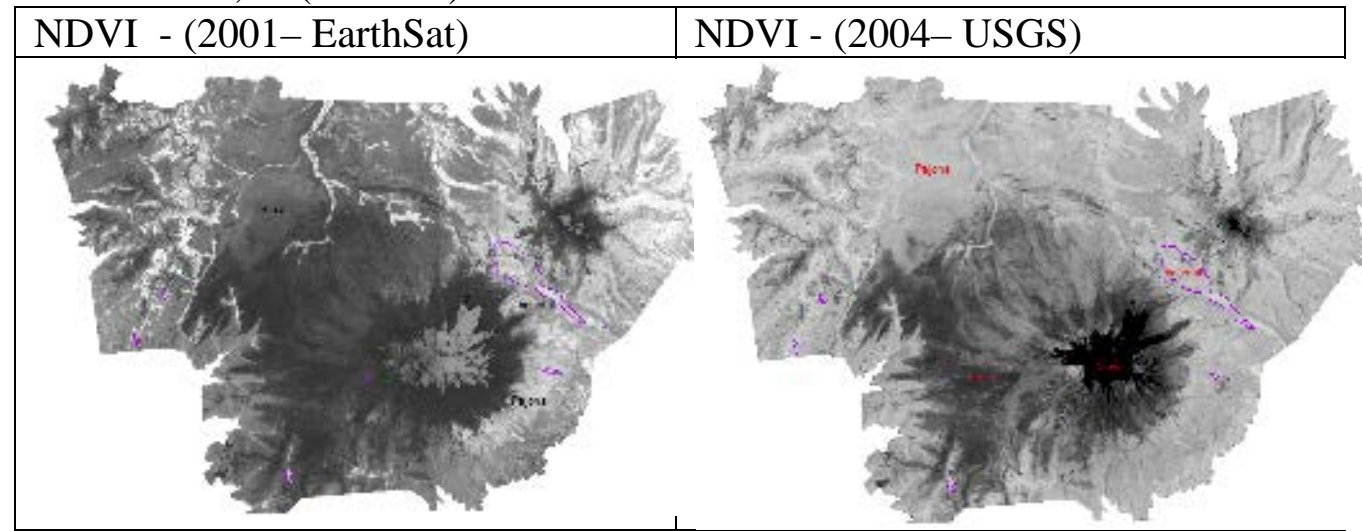

Figura 3. NDVI - Ortofoto RPFCH

Realizado por: Ing. Paulina B. Díaz M. MSc

Procesar imágenes para identificación de los bofedales de la etapa uno y dos y compararlos para la caracterización de la vegetación de los bofedales en el terreno y aplicar en base a la respuesta espectral de vegetación una clasificación óptima para los distintos tipos de vegetación, y 
específicamente conocer la extensión de los bofedales presentes en la Reserva, con el fin de inferir mejor la distribución de vicuñas.

En la identificación de los humedales el NDVI se utilizó como una imagen auxiliar para discriminar el agua de la tierra y otro tipo de coberturas (suelos desnudos, otra vegetación) con el objetivo de identificar los ecosistemas de humedales. Parra, A. (2010)

\section{Análisis de resultados}

A continuación, se presentan los resultados más destacables a nivel individual de cada bofedal, con el fin de mostrar la mayor claridad posible. Díaz. (2015:77-91)

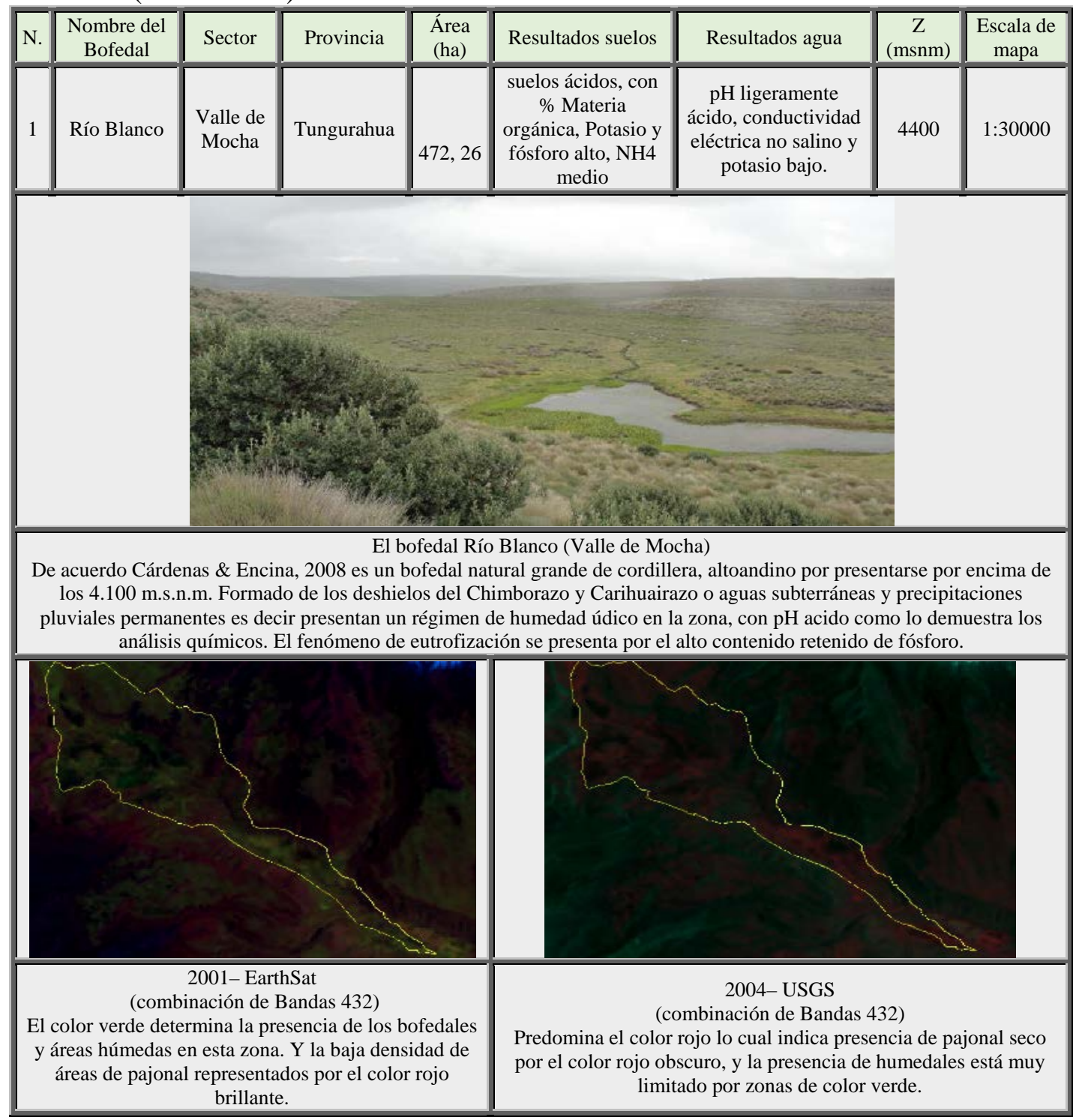




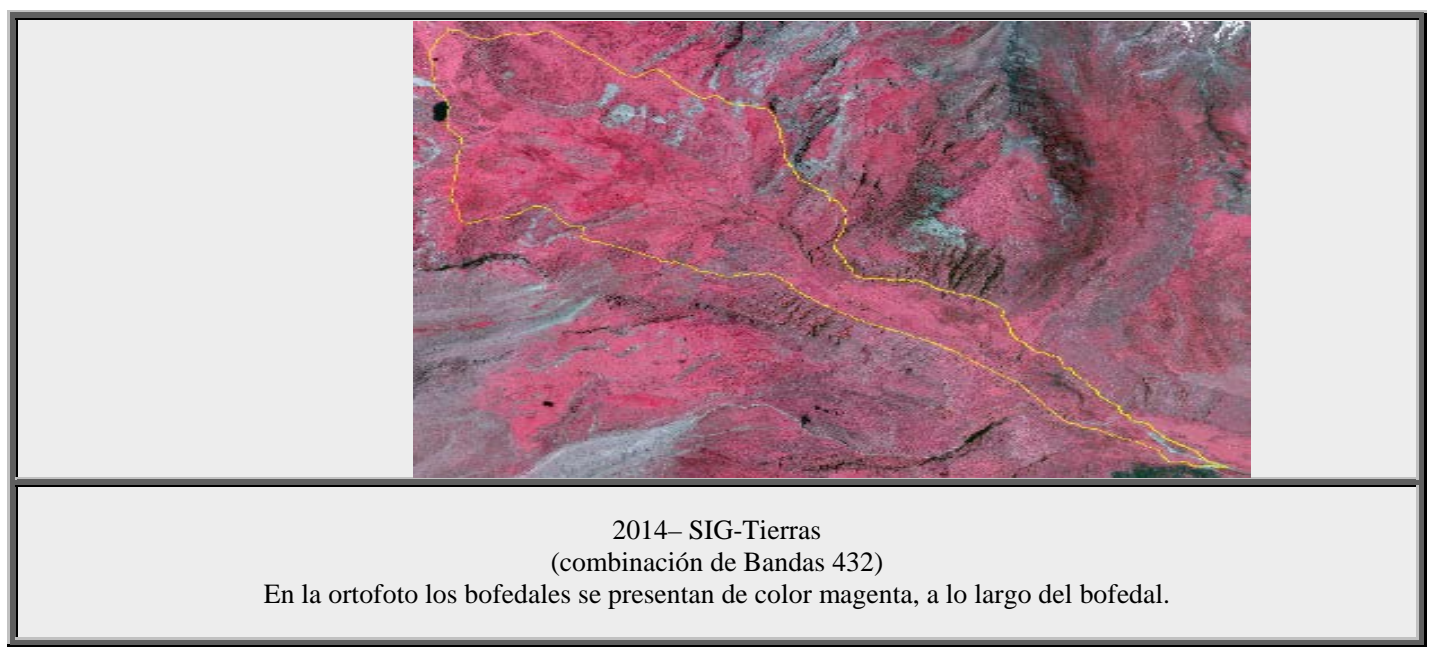

Figura 4. Ficha de resultados El bofedal Río Blanco (Valle de Mocha) - RPFCH Realizado por: Ing. Paulina B. Díaz M. MSc

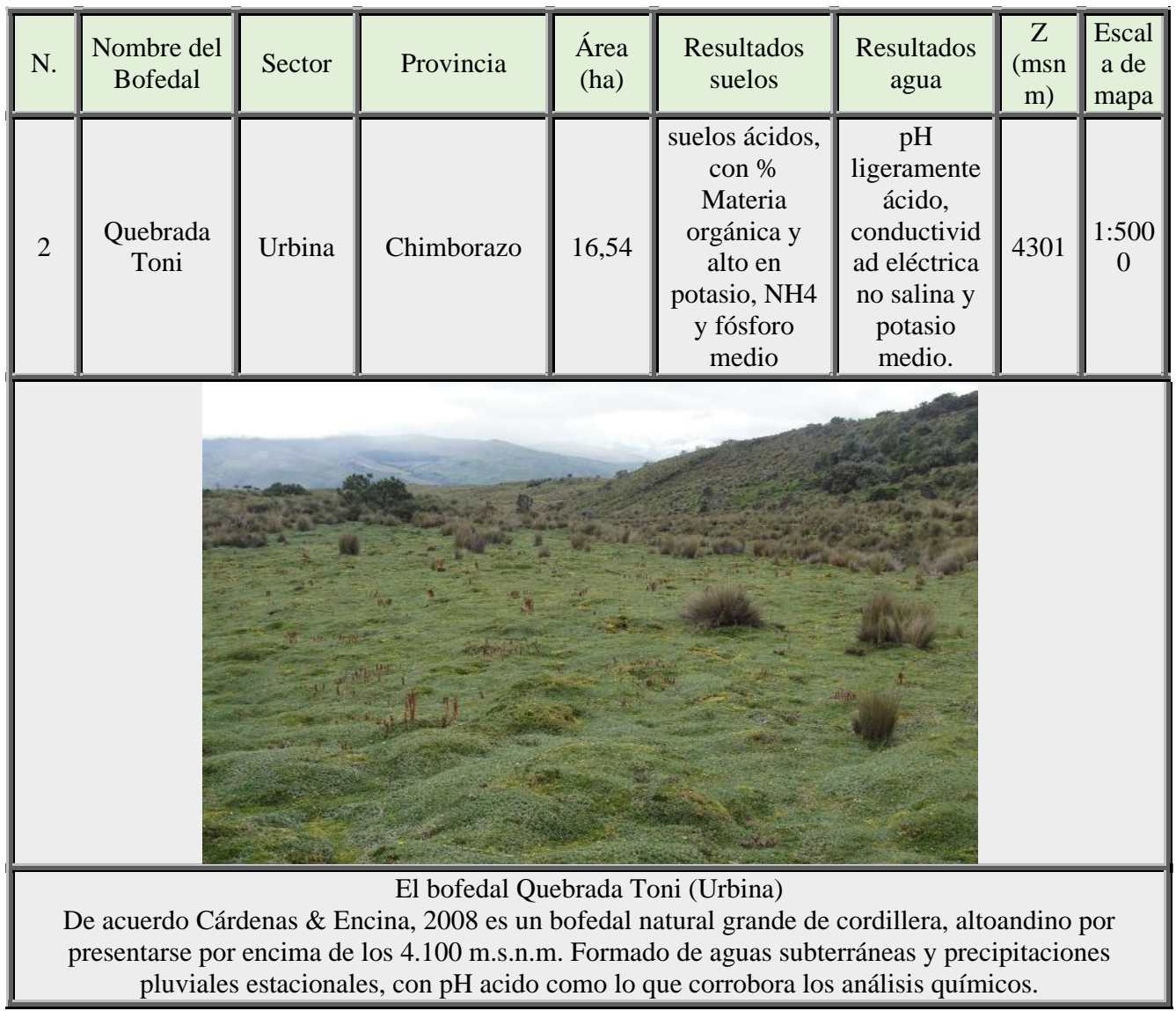




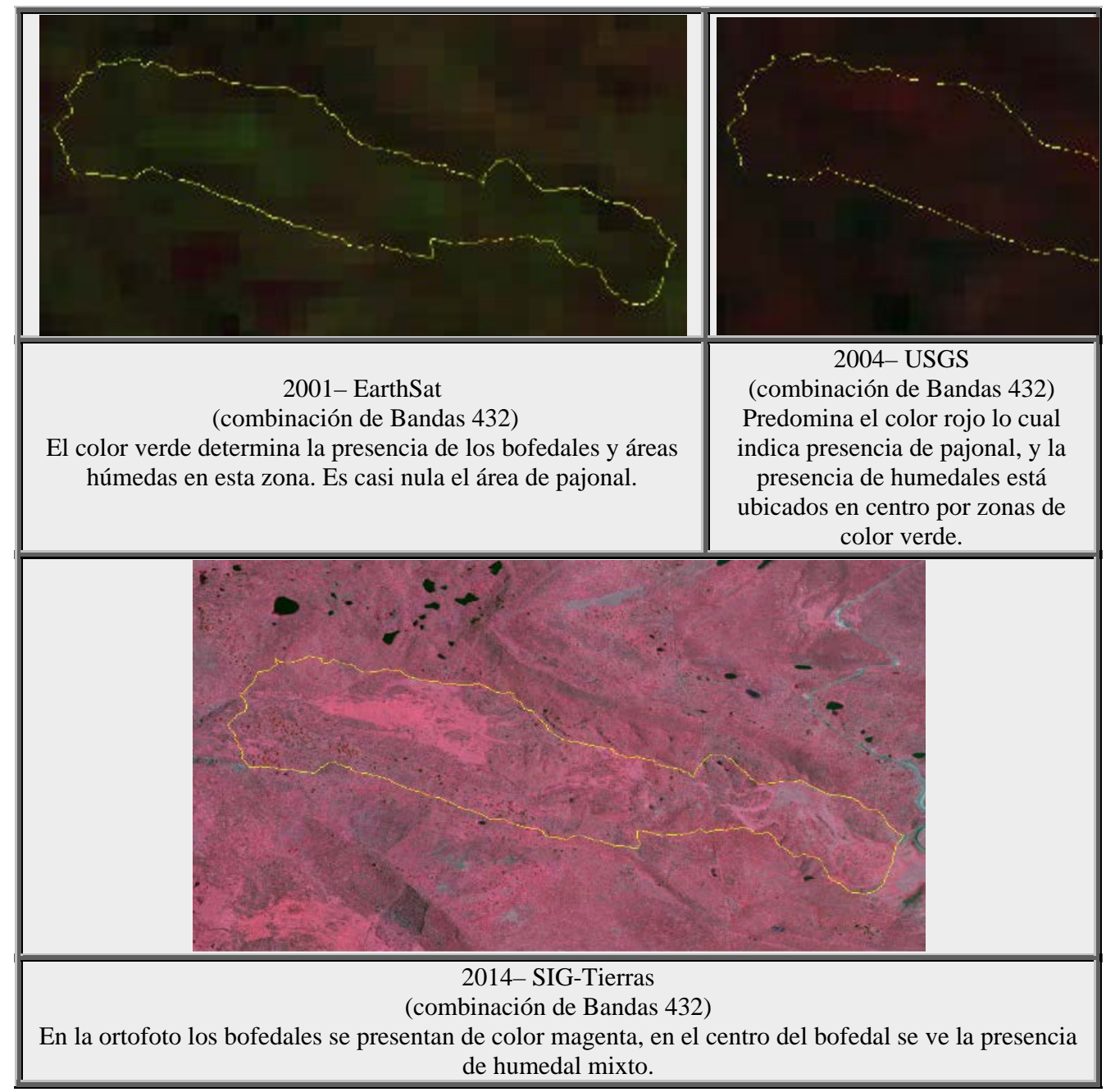

Fig. 5 Ficha de resultados bofedal Quebrada Toni (Urbina) - RPFCH Realizado por: Ing. Paulina B. Díaz M. MSc 


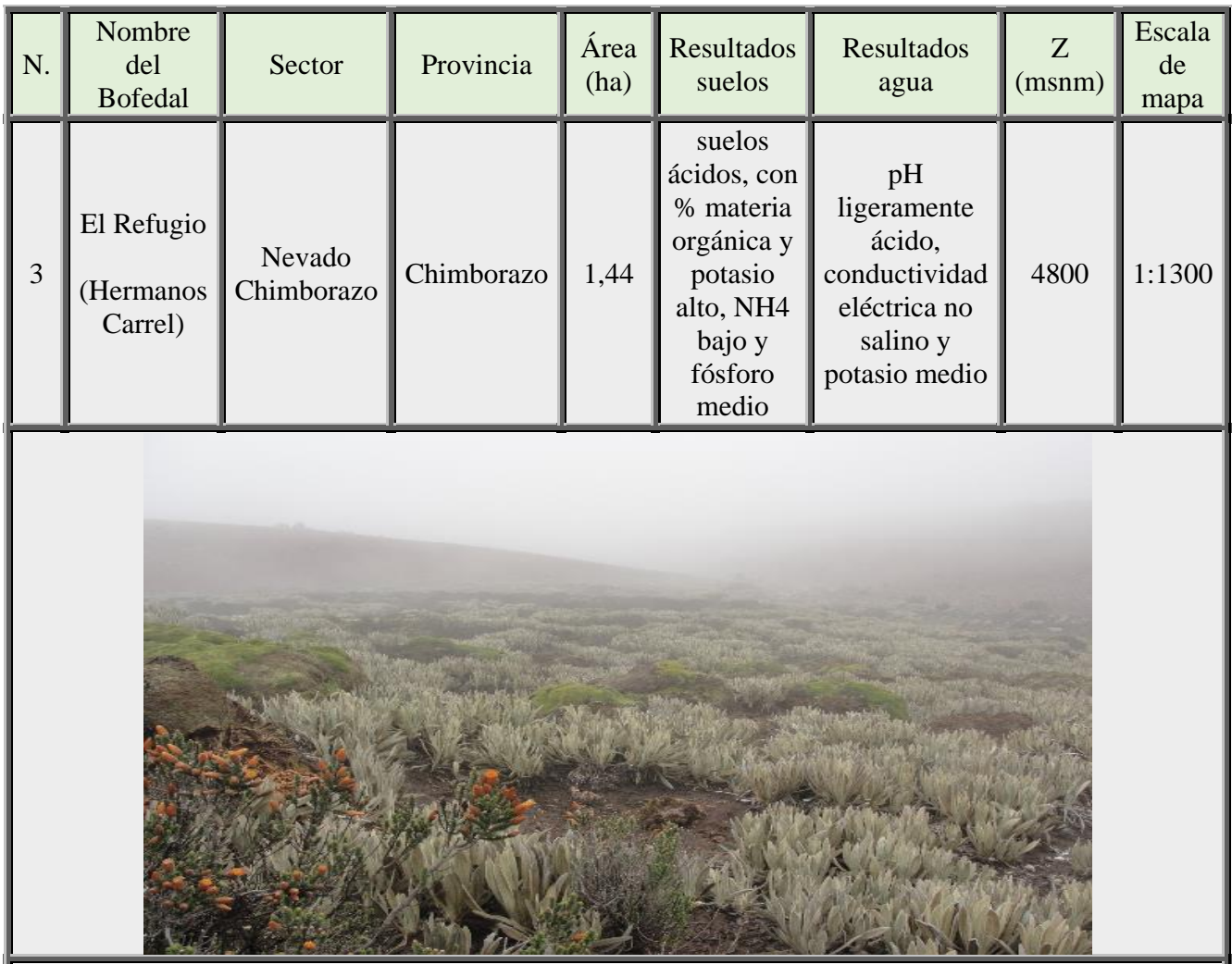

El bofedal El Refugio - (Hermanos Carrel)

De acuerdo Cárdenas \& Encina, 2008 es un bofedal natural pequeño de cordillera, altoandino por presentarse por encima de los 4.100 m.s.n.m. Formado manantiales que atraviesa la zona del bofedal.

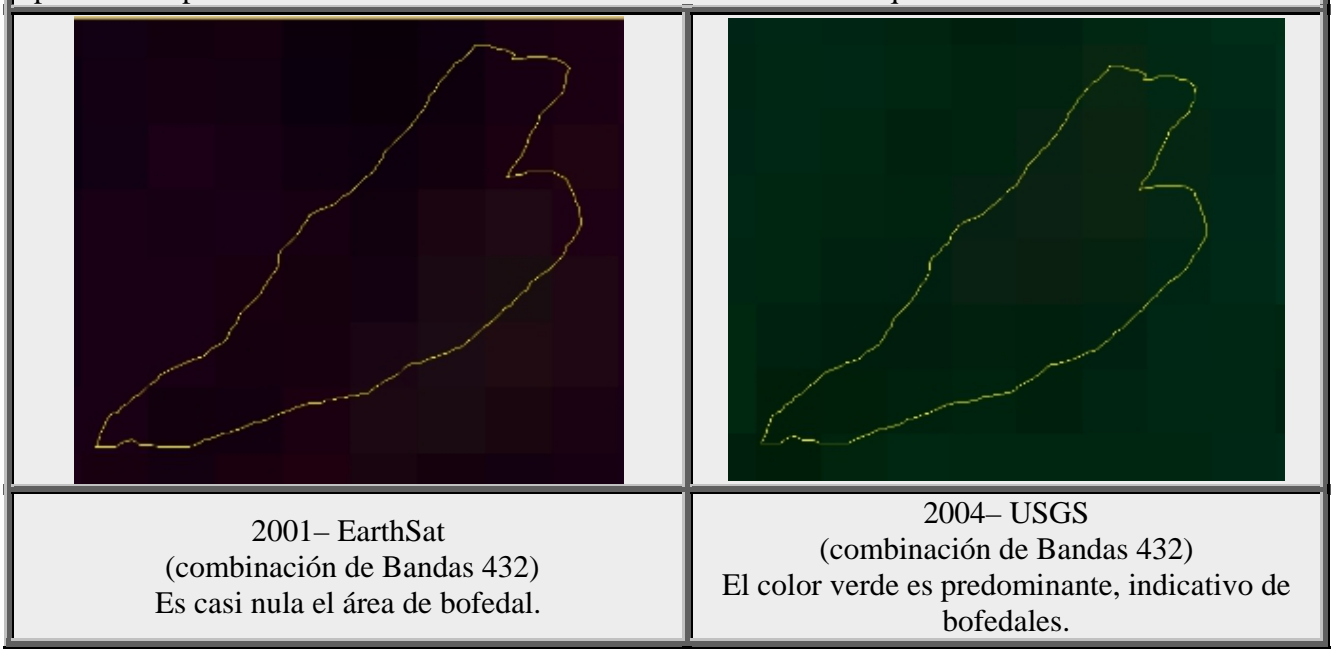




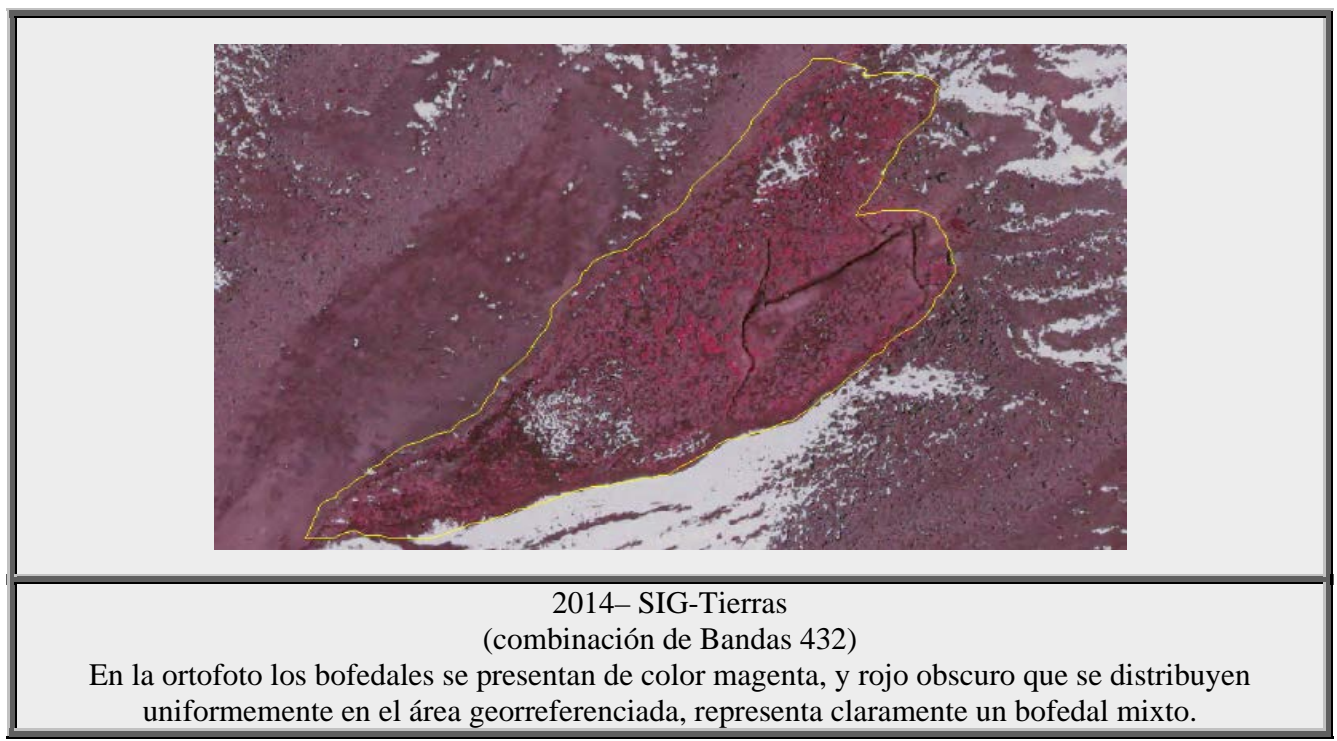

Figura 6. Ficha de resultados bofedal Quebrada Toni (Urbina) - RPFCH Realizado por: Ing. Paulina B. Díaz M. MSc

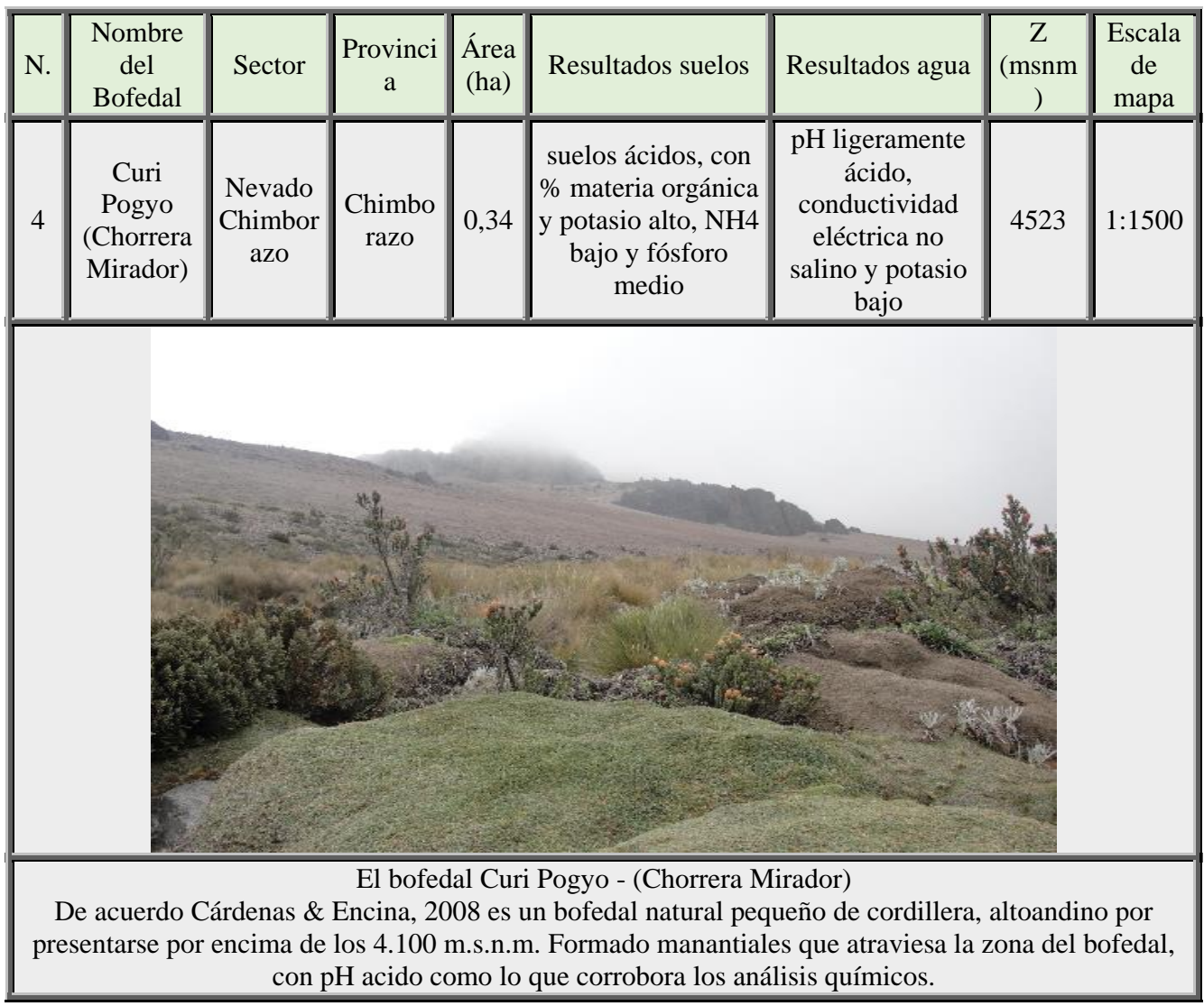




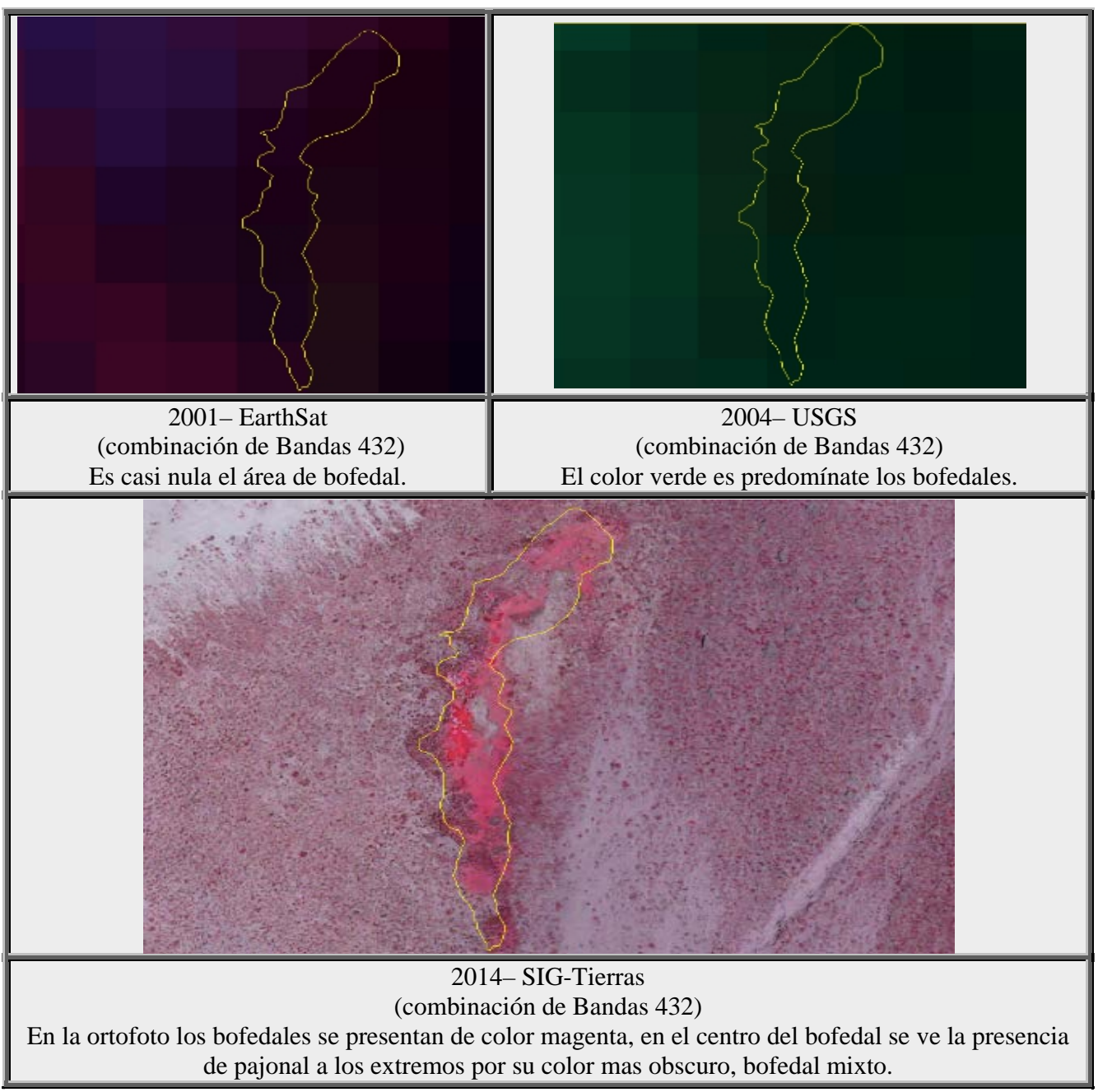

Figura 7. Ficha de resultados bofedal Curi Pogyo (Chorrera Mirador)- RPFCH

Realizado por: Ing. Paulina B. Díaz M. MSc 


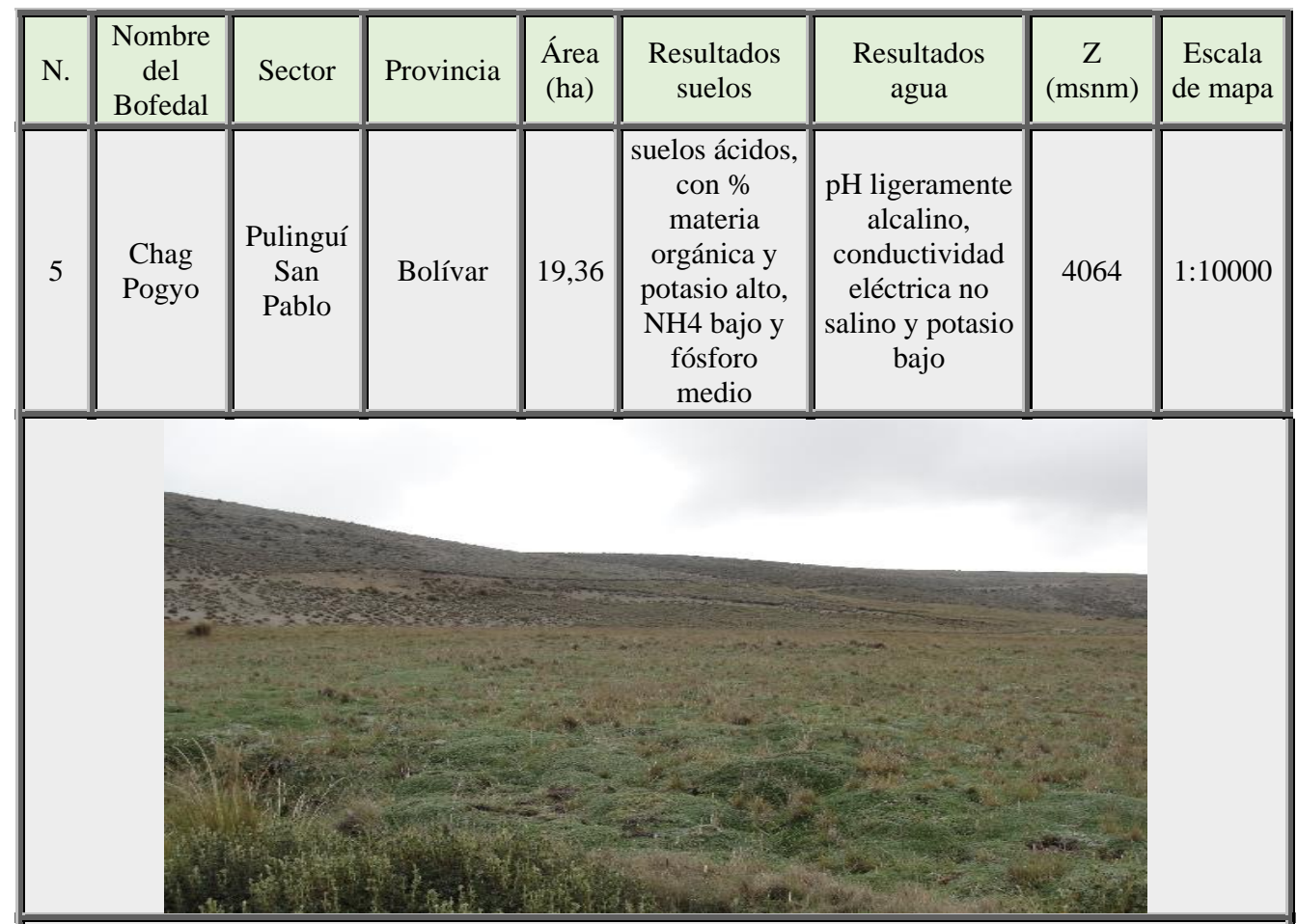

El bofedal Chag Pogyo

De acuerdo Cárdenas \& Encina, 2008 es un bofedal natural pequeño de valle, Altiplánicos por presentarse por debajo de los 4.100 m.s.n.m. Formado por precipitaciones pluviales, con pH alcalino.

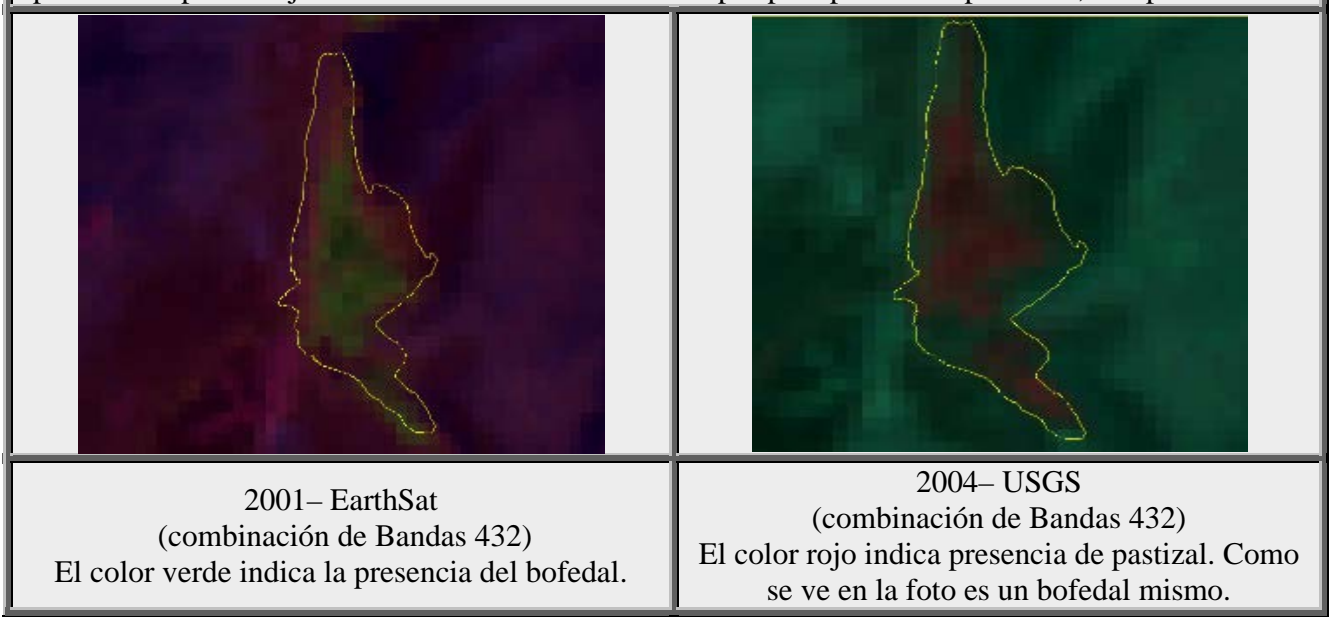




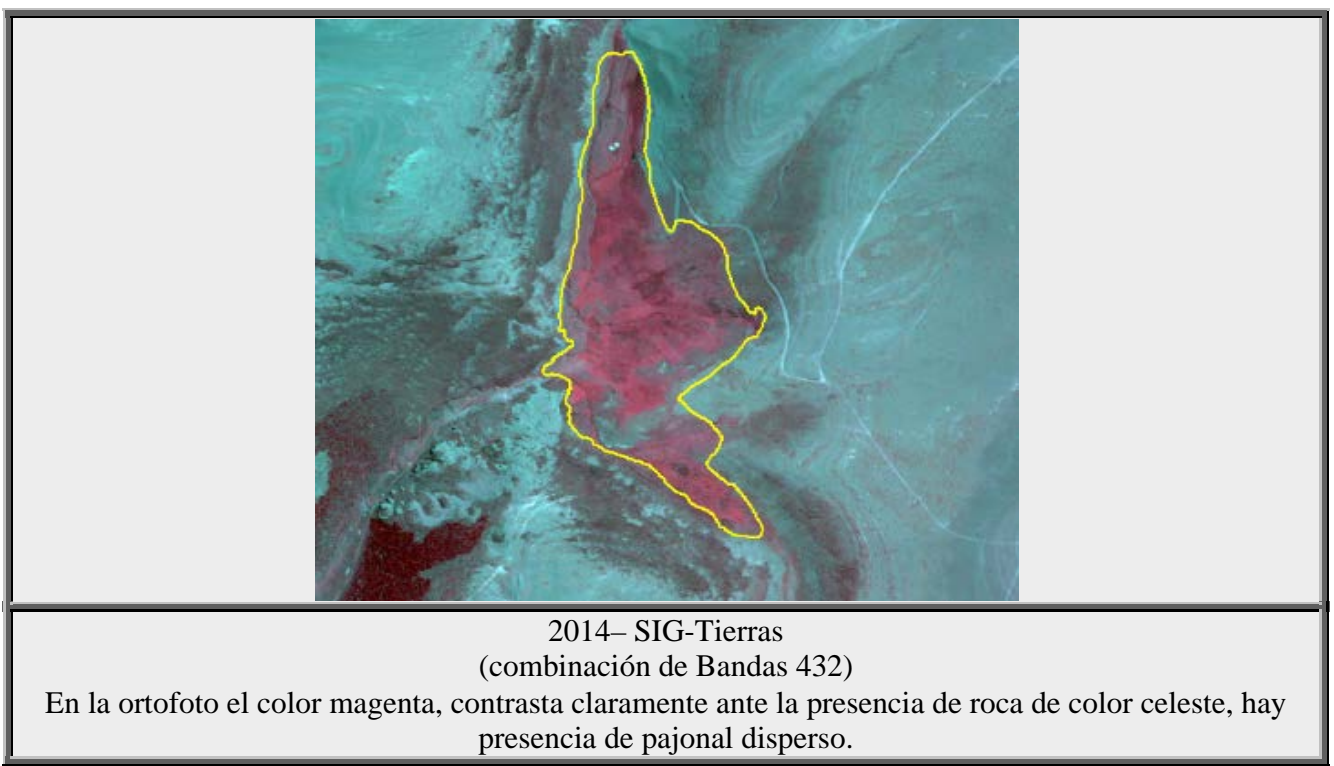

Figura 8. Ficha de resultados bofedal Chag Pogyo - RPFCH Realizado por: Ing. Paulina B. Díaz M. MSc

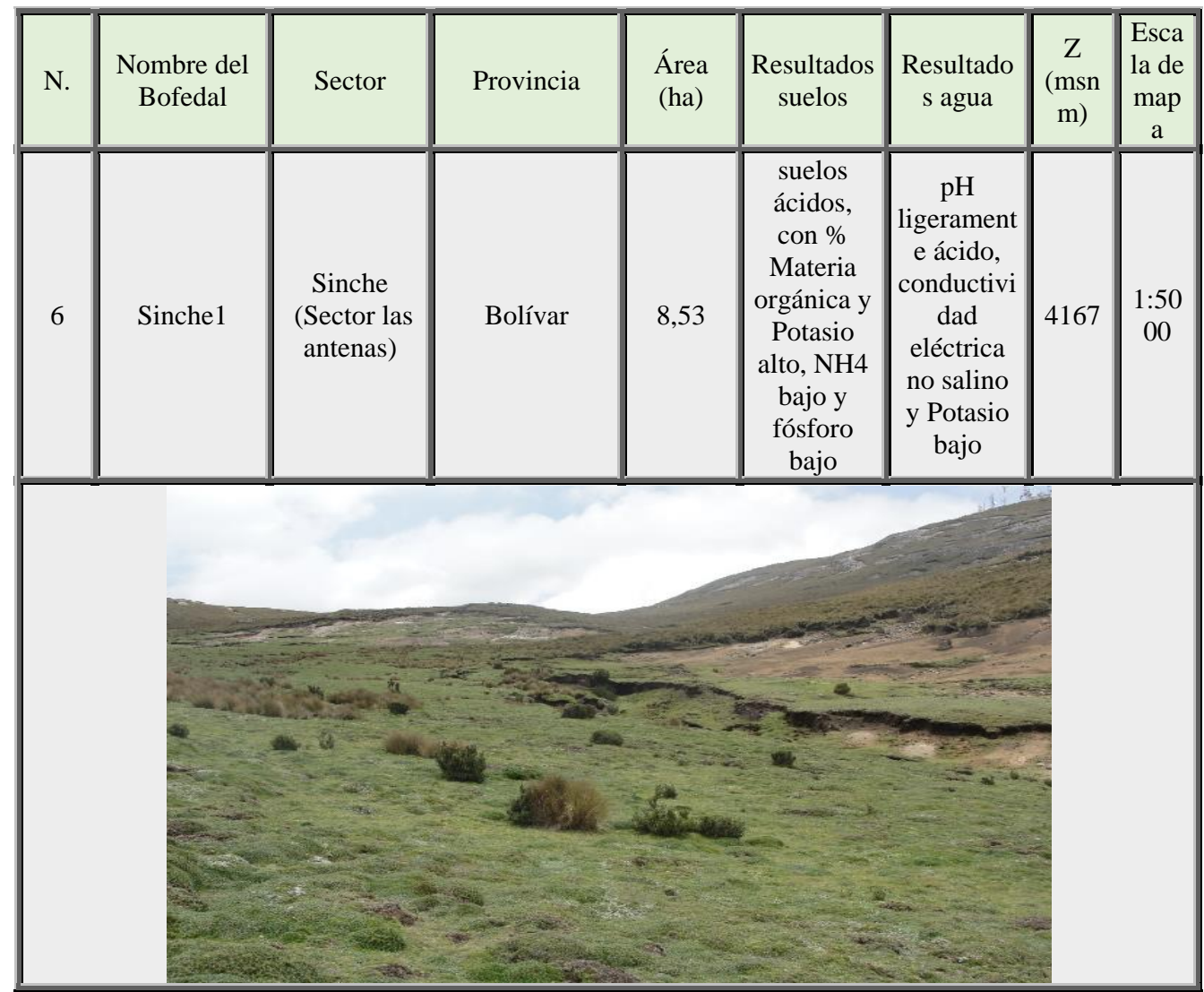


El bofedal Sinche - (Sector las antenas)

De acuerdo Cárdenas \& Encina, 2008 es un bofedal natural pequeño de valle, Altiplánicos por presentarse por debajo de los 4.100 m.s.n.m. Formado por precipitaciones pluviales, con pH alcalino.

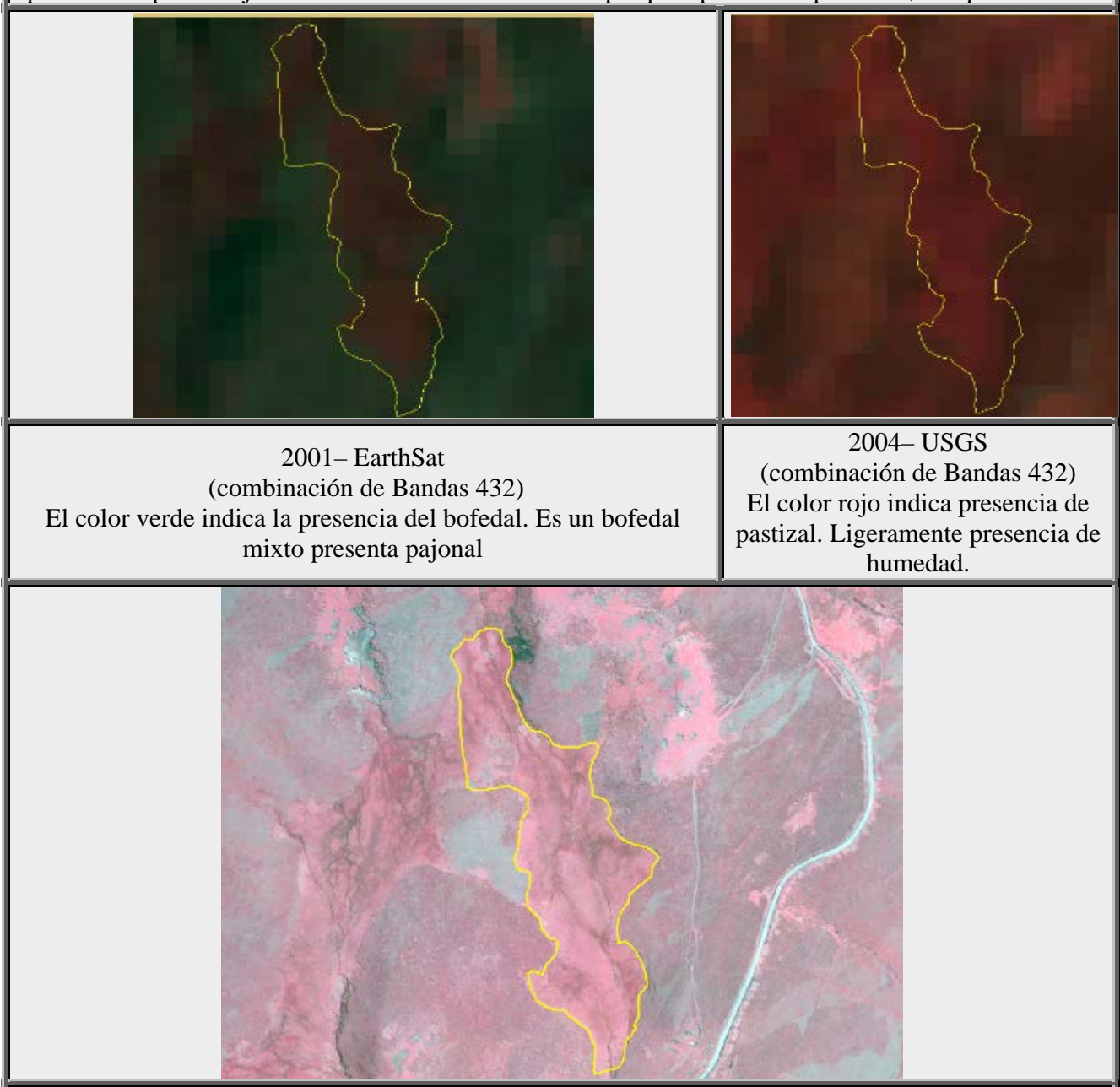

2014- SIG-Tierras

(combinación de Bandas 432)

En la ortofoto los bofedales se presentan de color magenta, en el centro del bofedal se ve la presencia de humedal mixto. 
Figura 9. Ficha de resultados bofedal Sinche - (Sector las antenas)- RPFCH Realizado por: Ing. Paulina B. Díaz M. MSc

\begin{tabular}{|l|c|c|c|c|c|c|c|c|}
\hline N. & $\begin{array}{c}\text { Nombre } \\
\text { del } \\
\text { Bofedal }\end{array}$ & Sector & Provincia & $\begin{array}{c}\text { Área } \\
\text { (ha) }\end{array}$ & $\begin{array}{c}\text { Resultados } \\
\text { suelos }\end{array}$ & $\begin{array}{c}\text { Resultados } \\
\text { agua }\end{array}$ & $\begin{array}{c}\mathrm{Z} \\
\text { (msnm) }\end{array}$ & $\begin{array}{c}\text { Escala } \\
\text { de } \\
\text { mapa }\end{array}$ \\
\hline 7 & Sinche2 & $\begin{array}{c}\text { Sinche } \\
\text { (Puente } \\
\text { Ayora) }\end{array}$ & Bolívar & 9,39 & $\begin{array}{c}\text { suelos ácidos, } \\
\text { con \% } \\
\text { materia } \\
\text { orgánica y } \\
\text { potasio alto, } \\
\text { NH4 bajo y } \\
\text { fósforo medio }\end{array}$ & $\begin{array}{c}\text { pH neutro, } \\
\text { conductividad } \\
\text { eléctrica no } \\
\text { salino y } \\
\text { potasio bajo }\end{array}$ & 3981 & $1: 5000$ \\
\hline & & & & & \\
\hline
\end{tabular}

El bofedal Sinche - (Puente Ayora)

(Puente Ayora) De acuerdo Cárdenas \& Encina, 2008 es un bofedal natural grande de valle, Altiplánicos por presentarse por debajo de los 4.100 m.s.n.m. Formado por precipitaciones pluviales, con $\mathrm{pH}$ neutro.

\begin{tabular}{|c|c|}
\hline $\begin{array}{c}\text { 2001- EarthSat } \\
\text { (combinación de Bandas 432) }\end{array}$ & $\begin{array}{c}\text { 2004- USGS } \\
\text { (combinación de Bandas 432) }\end{array}$ \\
\hline $\begin{array}{c}\text { El color verde indica la presencia del bofedal. Pero } \\
\text { predomina el pajonal. }\end{array}$ & $\begin{array}{c}\text { El color rojo indica presencia de pastizal. Casi } \\
\text { no hay presencia de bofedales. }\end{array}$ \\
\hline
\end{tabular}




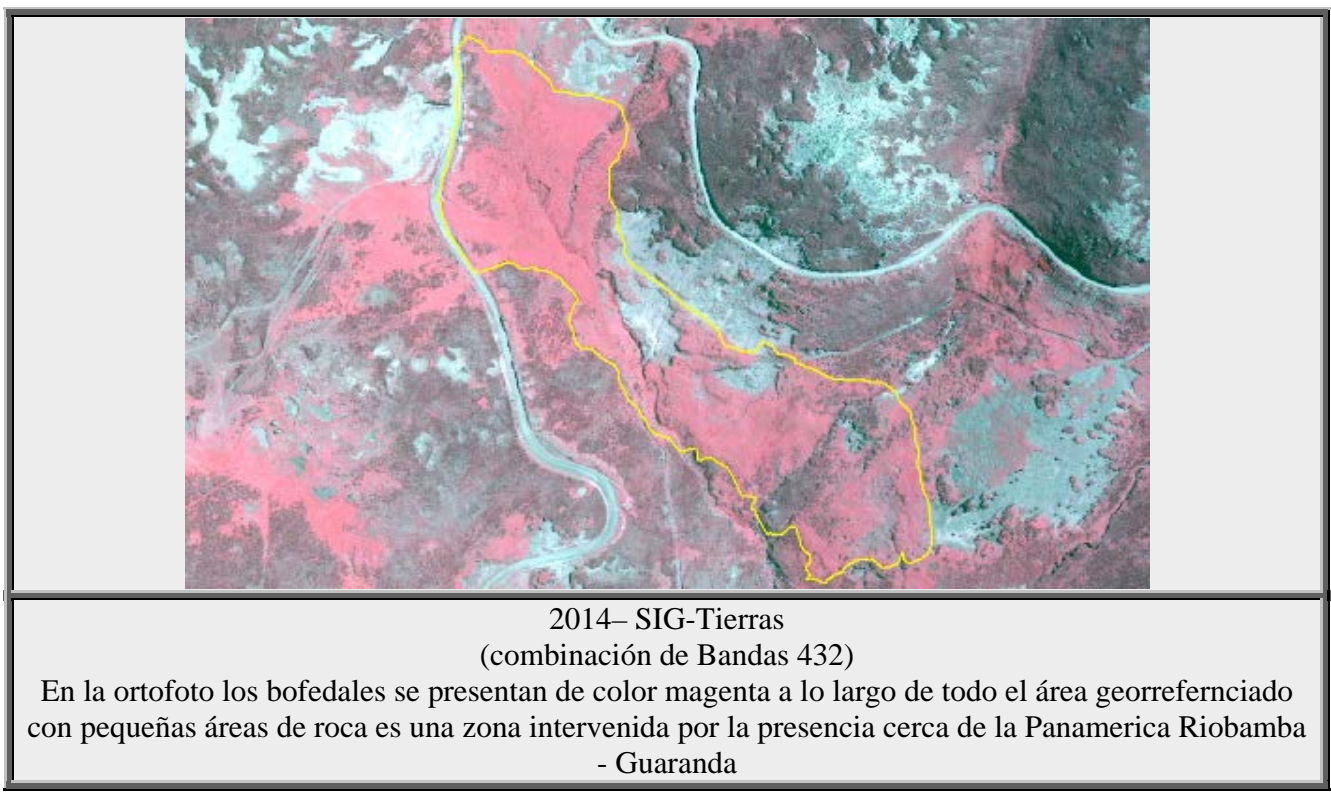

Figura 10. Ficha de resultados bofedal Sinche (Puente Ayora) - RPFCH Realizado por: Ing. Paulina B. Díaz M. MSc

\section{Conclusión}

La metodología usada mediante los SIG y teledetección aplicadas al estudio de los bofedales permiten determinar con alta precisión los tipos y la extensión de coberturas existentes por períodos. Se puede establecer con las imágenes satelitales y sus diferentes procesamientos que los bofedales en la reserva están ampliamente distribuidas.

La metodología del análisis multitemporal al estudio de la caracterización de bofedales permite aclarar y determinar mejor los cambios producidos en los años de estudio, así como un preámbulo para discriminar las clases de estudio de la zona, para la clasificación posterior de imágenes. Yánez. P, Benavides. J, Quishpe. C. (2013:10)

La metodología de clasificación de imágenes tanto supervisada y no supervisada para toda el área de la reserva, evidenció un mejor resultado de información con la clasificación supervisada la cual discrimina la evolución más fiable de los bofedales y más eficiente para determinar las unidades estudiadas, dando una superficie aproximada de bofedales de 1483.94 ha. Y los siete bofedales estudiados in situ representan el 35.57\% (527.87 ha) del total de Bofedales al 2004 presente en la reserva.

El estudio de las imágenes con NDVI refleja un aumento significativo de vegetación en los periodos estudiados ante la reducción de las otras clases, lo cual corrobora la ortofoto del 2014 procesada. Estos resultados se pueden justificar con el aumento de pajonal en la reserva que incluso en la zona rocosa se ve un aumento de vegetación en la RPFCH. 
La metodología para la caracterización ecológica de bofedales, con la utilización de la teledetección y los SIG permitieron determinar que en la RPFCH presentan dos tipos de bofedales en la reserva: cinco bofedales naturales de cordillera altoandino (bofedales Río Blanco (Valle de Mocha), Quebrada Toni (Urbina), El Refugio (Hermanos Carrel), Curi Pogyo (Chorrera Mirador) y Sinche (Sector las antenas), por presentarse por encima de los 4.100 m.s.n.m.). Izurieta (2005:25) y dos bofedales naturales de valle Altiplánico (Chag Pogyo (Pulinguí San Pablo) y Sinche (Puente Ayora) por presentarse por debajo de los 4.100 m.s.n.m.) Cárdenas \& Encina, 2008:8, Sierra R. (ed.). (1999:)

\section{References:}

1. Acuerdo Ministerial: No 437 del 26 de octubre de 1987, publicado en el Registro Oficial No 806 del 9 de noviembre de 1987 Disponible en:

http://suia.ambiente.gob.ec/documents/10179/241417/35+RESERVA +DE+PRODUCCION+DE+FAUNA+CHIMBORAZO.pdf/5d92208c -6ee3-42ee-a7be-de550d04c3e1. 1987,5p

2. Alzerraca. H. (2001). Características y distribución de los bofedales en el ámbito boliviano del sistema T.D.P.S. MAPZA-GTZ-Parque Nacional Sajama-SERNAP, La Paz, Bolivia. pp 82-151.

3. Briones, E., J. Gómez, A. Hidalgo, D. Tirira, \& A. Flachier. 2001. Inventario de Humedales del Ecuador. Segunda Parte. Humedales Interiores de la provincia de El Oro. Convención de RAMSAR/INEFAN/EcoCiencia. Quito, Ecuador.

4. Bradley, R.S., et al (2006). Climate Change. Threats to Water Supplies in the Tropical Andes. Science 312: 1755-1756

5. Cardenas, M., Encina, G. (2008) Gestion sustentable de bofedales del salr del Huasco, Centreo de estudios para el desarrollo, Santiago de chile pg 5,8,10,13.

6. Convención de Ramsar y Grupo de Contacto EHAA. 2008. Estrategia Regional para la Conservación y Uso Sostenible de Humedales Altoandinos. Gobiernos de Ecuador y Chile, CONDESAN y TNCChile.

7. Coronel, J., Declerck, S., Maldonado, M., Ollevier, F., Brendonck, L. (2004). Temporary shallow pools in high Andes "bofedal” peatlands: a limnological characterization at different spatial scales. Archives des Sciences 57: 85-90.

8. Cuesta-Camacho F., Peralvo M., Ganzenmüller A., Sáenz M., Novoa J., Riofrío G. y K. Beltrán. (2007). Identificación de vacíos y áreas prioritarias para la conservación de la biodiversidad terrestre en el Ecuador continental. pg. 15-36. 
9. Díaz, P. (2015) Caracterización ecológica de los Bofedales, como hábitat vital de las Vicuñas en la Reserva de Producción de Fauna Chimborazo con la aplicación de herramientas de SIG y teledetección.2015 pg.15-146. Disponible en: http://repositorio.usfq.edu.ec/bitstream/23000/4102/1/112640.pdf

10. ECOLAP y MAE. (2007). Guía del Patrimonio de Áreas Naturales Protegidas del Ecuador. ECOFUND, FAN, DarwinNet, IGM. Quito, Ecuador.

11. Echeverría, H. 2008. La Convención Ramsar en el Ecuador. Guía sobre la conservación y uso racional de los humedales. Centro Ecuatoriano de Derecho Ambiental. Quito, Ecuador.

12. Flachier et al. (2009) Caracterización Ecológica de las Turberas y Bofedales del Sistema de Humedales Amaluza, Nudo de Sabanilla, Provincia de Loja, Ecuador. pg 9.

13. Flores D. (2002). Identificación y análisis de cambios en bofedales de la Cordillera Occidental y del Altiplano de Bolivia. Tesis Maestría Profesional en "Levantamiento de recursos hídricos (Manejo y conservación de cuencas)” Thesis, Universidad Mayor de San Simón, Internacional Institute for Infraestructural Hydraulic and Environmental Engineering, Santa Cruz.

14. García, M.P. \& Pérez, M.E. (1999). Estudio mediante imágenes TM del entorno de Villacañas (Toledo). Revista de Teledetección, 11, pp. 13-22

15. Hoffmann, D. (2010). El cambio climático y las áreas protegidas de Bolivia; in: Beck, S.G., N. Paniagua, R.P. López \& N. Nagshiro (Eds.): Biodiversidad y Ecología en Bolivia

16. Izurieta X. 2004. En: Mena-Vásconez, P. and D. Ortiz (eds). 2004. Páramo y humedales. Serie Páramo $\mathrm{N}^{\circ} 14$. Grupo de Trabajo en Páramos del Ecuador (GTP). Ediciones Abya-Yala. Quito, Ecuador. Disponible en: http://infoandina.mtnforum.org/sites/default/files/publication/files/LI BRO_TURBERAS.pdf

17. Izurieta X. (Ed.). (2005). Turberas Altoandinas. Espacios frágiles de Vida y Cultura. Proyect "Peatlands in the Tropical Andes". Global Peatland Initiavite/NCIUCN/ECOPAR/GRUPO PARAMO. Quito, Ecuador.

18. MAE. (2006). Política y estrategia nacional para la conservación y el uso racional de los Humedales en el Ecuador. Ministerio del Ambiente/Comité Nacional Ramsar, Quito.

19. MAE. (2011). Plan de Acción Nacional para el manejo y conservación de la vicuña enel Ecuador. (En línea). Disponible en: http://cites.org/esp/cop/16/inf/S-CoP16i-45.pdf. pgs.7,12 
20. McLaren, B., Cayambe O., MacNearney., Cayambe, L., Guamanshi, O., Concha, C., Gualancaña, S. y Lema, X. Observaciones y monitoreo de las vicuñas 67en la Reserva de Producción de Fauna Chimborazo, Ecuador (Informe2012-2013). "Inédito”, 2013,44p.

21. Murillo, K. y D. Jukofsky. s/a. (2001). Guía de periodismo sobre Humedales de Centroamérica. Rainforest Alliance / US Fish and Wildlife Service

22. Parra, A. (2010). Identificación y delimitación de humedales lénticos en el valle alto del río cauca mediante el procesamiento digital de imágenes de

Satélite. Escuela de Ingeniería Civil y Geomática Universidad del Valle, Cali, Colombia. Revista EIDENAR, Disponible en: http://revistaeidenar.univalle.edu.co/revista/ejemplares/9/k.htm

23. Pérez, M. (2011). Aplicaciones de la teledetección y SIG en la caracterización de humedales en la Reserva de la Biosfera de la Mancha Húmeda. Tesis Maestría en tecnologías de la información geográfica. Universidad Complutense De Madrid, Madrid. Disponible en: http://eprints.ucm.es/13964/2/TFM_Maria_Perez.pdf

24. Perry, C., Lautenschlager, L. (1984). Functional equivalence of spectral vegetation indices. Remote Sensing of Environment, 14, 169-182. Disponible en: http://dx.doi.org/10.1016/00344257(84)90013-0

25. Prieto, G., Alzérreca H., Laura J., Luna D. y Laguna. S. (2002). Características y Distribución de los Bofedales en el Ámbito Boliviano del Sistema T.D.P.S. En: Rocha O. y C. Suárez (eds.). (2003). Pp. 117-150.

26. Secretaria De La Convención Ramsar. (2004). Manuales Ramsar para el uso racional de los humedales. Secretaría de la Convención Ramsar, Gland (Suiza)

27. Sierra R. (ed.). (1999). Propuesta Preliminar de un Sistema de Clasificación de Vegetación para el Ecuador Continental. Proyecto INEFAN/GEF - BIRF y EcoCiencia. Quito, Ecuador.

28. Sig tierras, Ecuador. (septiembre de 2013-2014). Restitucion aero fotográfica del Ecuador. Quito, Pichincha, Ecuador.

29. Slater A. (2007). Identificación y análisis de cambios en bofedales de la cordillera occidental y del altiplano de Bolivia. Tesis para el Titulo con Honores de Licenciatura en Estudios del Ambiente (Conservación del Bosque). Universidad de Lakehead Thunder Bay. Ontario, Canadá. pp. 35-98

30. Squeo, F.; Warner, B.; Aravena, R.; Espinoza, D. (1996). Bofedales: turberas de alta montaña de los Andes Centrales. Revista Chilena de 
Historia Natural: 79, $245 \quad$ Disponible en: http://dx.doi.org/10.4067/S0716-078X2006000200010

31. Vega, L. (2006). "La Teledetección aplicada al Inventario de Humedales”, [en línea]. Mapping interactivo. Revista Internacional de Ciencias de la Tierra.

32. Yánez, P., Benavides. J, Quishpe. C. (2013) Caracterización Multivariada De Las Entidades Que Conforman El Patrimonio De Áreas Naturales Del Estado Ecuatoriano: Fase I. Revista de ciencias de la vida UPS: $10 . \quad$ Disponible en: http://lagranja.ups.edu.ec/index.php/granja/article/view/354/213 